\title{
Taxonomy and Clinical Spectra of Fusarium Species: Where Do We Stand in 2014?
}

\author{
Anne D. van Diepeningen - Abdullah M. S. Al-Hatmi • \\ Balázs Brankovics • G. Sybren de Hoog
}

Published online: 5 August 2014

(C) The Author(s) 2014. This article is published with open access at Springerlink.com

\begin{abstract}
With the recent change of the botanical code for the names of algae, fungi, and plants, fungi are no longer allowed to have multiple names for their different reproductive stages. Here we discuss that under the new nomenclatural rules and for taxonomic stability, Fusarium is to be preferred above names for some of its known sexual stages like Haemonectria and Gibberella. The genus Fusarium contains emerging etiological agents of disease ranging from onychomycoses, skin and eyeinfections, to deep localized and disseminated infections. Deep infections occur nearly exclusively in immunocompromised patients, while remaining infections primarily affect healthy individuals. Within the large genus, at least seven species complexes comprising multiple species have been implicated in human and animal infections. In this review we give an overview of currently known opportunistic Fusarium species and the infections they cause.
\end{abstract}

\footnotetext{
A. D. van Diepeningen $(\varangle) \cdot$ A. M. S. Al-Hatmi • B. Brankovics • G. S. de Hoog CBS-KNAW Fungal Biodiversity Centre, Uppsalalaan 8, 3584CT Utrecht, The Netherlands e-mail: a.diepeningen@cbs.knaw.nl

A. M. S. Al-Hatmi

e-mail: a.alhatmi@cbs.knaw.nl

B. Brankovics

e-mail: b.brankovics@cbs.knaw.nl

G. S. de Hoog

e-mail: de.hoog@cbs.knaw.nl
}

A. M. S. Al-Hatmi · G. S. de Hoog
Institute of Biodiversity and Ecosystem Dynamics, University of
Amsterdam, Amsterdam, The Netherlands

A. M. S. Al-Hatmi

Ministry of Health, Muscat, Oman
Keywords Disseminated infection · Emerging fungal pathogen · Fusarioses $\cdot$ Fusarium avenaceum $\cdot$ Fusarium chlamydosporum $\cdot$ Fusarium dimerum species complex . Fusarium fujikuroi species complex $\cdot$ Fusarium incarnatum-equiseti species complex · Fusarium lateritium . Fusarium oxysporum species complex $\cdot$ Fusarium semitectum · Fusarium solani species complex $\cdot$ Fusarium sporotrichioides $\cdot$ Incidence $\cdot$ Keratitis $\cdot$ Nomenclatural stability $\cdot$ Onychomycosis $\cdot$ Population studies

\section{An Introduction to Fusarium Taxonomy}

For centuries, systematics has been based on morphological characteristics, and hence fungi were grouped mostly according to visible (reproductive) structures. As many fungal species exhibit both asexual and sexual reproduction-which may occur independently from each other-they were

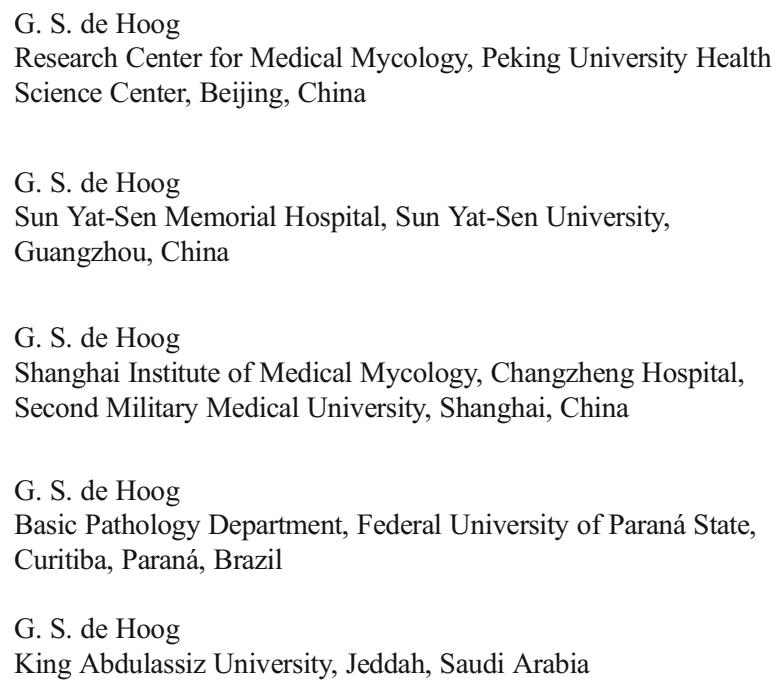


allowed to carry separate names for different parts of the life cycle. DNA analysis has become indispensable, which has led to discoveries of genetic links between previously separated entities. Where in the past, anamorphic and teleomorphic names clarified relationships between species, they have become rather confusing today.

Due to recent changes in the International Code of Nomenclature for Algae, Fungi, and Plants, as of January 2013 every fungal species is allowed to have only a single name [1]. Furthermore, where formerly, preference would be given to the sexual name over the asexual one, exceptions are now allowed, e.g., for sake of preservation of older names, but also for widely used genus and species names. A huge task now lies in the determination of what is the best name for each species.

For Fusarium, a plea has been made to conserve the name Fusarium above all linked teleomorphic names like Heamonectria and Gibberella [2•]. For nomenclatural stability, assembled experts in the fields of plant pathology, mycotoxins, and human and animal pathology preferred to maintain the best known - or perhaps we should say, for its variety of deleterious effects, most infamously known-name: Fusarium. Hence, use of the name Fusarium is unproblematic, but generic borderlines are yet to be determined. For medically relevant fungi, an extra plea has been made to reduce the number of unnecessary name changes and to keep well-known names as stable as possible [3•].

In this era of genomics, it is well-accepted to use a multilocus sequence typing (MLST) approach in combination with the genealogical concordance phylogenetic species recognition (GCPSR) principle [4] rather than morphology to recognize species and to sort out their relationships. For many of the morphologically defined Fusarium species, we know from MLST-GCPSR that we are dealing with species complexes of morphologically (nearly) indistinguishable siblings rather than with single species. Fusarium was one of the first fungal groups where the term 'species complex' was commonly used for closely related species [e.g.,[ 7, 8]. Within such a species complex different MLST-haplotypes can be recognized that, after careful consideration, may be established as separate species. An example of this is the recent recognition of $F$. keratoplasticum and $F$. petroliphilum, two opportunistic pathogens in the Fusarium solani species complex [5].

Geiser et al. [2•] in their proposal to preserve the genus Fusarium in a robust way maintain a wide definition of the genus Fusarium (Fig. 1A; node F1 is the hypothetical ancestor for the entire genus). In this way, the terminal Fusarium clade comprises at least 20 strongly supported species complexes and nine monotypic lineages [6], including seven Fusarium species complexes associated with described cases of human infections: the $F$. dimerum species complex (FDSC), the F. solani species complex (FSSC), the Fusarium oxysporum species complex (FOSC), the F. fujikuroi species complex
(FFSC, encompassing F. proliferatum and F. verticillioides), the $F$. incarnatum-equiseti species complex (FIESC), the F. chlamydosporum species complex (FCSC), and the complex including F. sporotrichioides (FSAMSC). Only a few other Fusarium species outside these species (complexes) have occasionally been implicated in human or mammal infections. In this review we will use this broadest definition (Fig. 1A-block A) of the genus Fusarium.

Alternatively, a more narrow definition of the genus Fusarium could be made, placing the border of the genus, for instance, at nodes F2 or F3 in Fig. 1A. Under these scenarios there are two species complexes that include human opportunists and that would then need reallocation into new genera: The first group would be FDSC (Fig. 1A-block D), including $F$. dimerum, $F$. delphinoides, and others. The other option would exclude also the FSSC (Fig. 1A-block C), which would exclude the largest and most important group with respect incidence: best known as $F$. solani sensu lato, leaving everything linked with a Gibberella-like teleomorphic stage (Fig. 1A-block A) as core-Fusarium species. Nodes F1, F2, and $\mathrm{F} 3$ receive different levels of support based on phylogenetic analyses like maximum likelihood, maximum parsimony, and Bayesian analysis, but as none of these are $100 \%$ conclusive, the definition of Fusarium is kept as broad as possible $[2 \cdot 6]$.

\section{Identification of Fusarium Species}

The most typical feature of the genus Fusarium is its unique spindle- or canoe-shaped, multicellular macroconidia. However, these macroconidia are not always present, and differently shaped, single-celled or multicellular micro- and/ or mesoconidia may also be formed as well as (pseudo-)chlamydospores. The shape of conidiophores, i.e., the structures on which conidia are formed, may differ between species. Some species are homothallic and produce fruiting bodies with ascospores, while heterothallic species need a suitable partner to produce such structures [7]. Keys have been published for the recognition of clinical Fusarium species [e.g.,[ 4, 83]. These keys are based on morphological structures and require expert training. Fungi have to be grown on standardized, specialized media, and the formation of distinguishing features may require up to 6-8 weeks, rendering precise identification clinically redundant. Besides, morphological recognition of Fusarium species in a hospital setting is often impossible by degeneration of colony morphology or by conversion to a 'pionnotal' phenotype [8].

For DNA-based identification of fungi in general, the barcoding and recognition region is the internal transcribed sequence (ITS) region. However, for Fusarium spp. this region is too conserved and may not even distinguish between species complexes, let alone down to the species level. For 


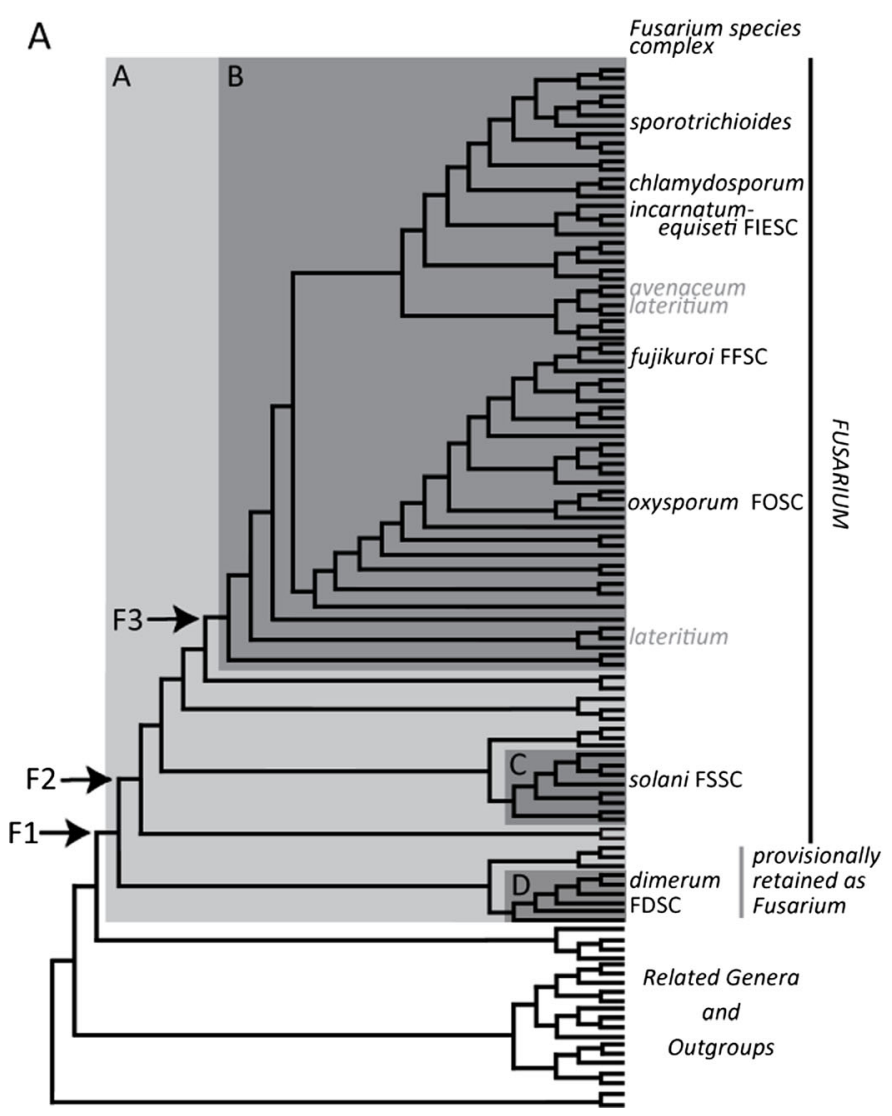

Fig. 1 a Cladogram representation of the (provisional) genus Fusarium $[2 \cdot, 6]$ with the location of Fusarium species (complexes) reported multiple times to have been involved in human infections (black) or just once (grey). $b$ - $c$ These Fusarium spp. are emerging fungal pathogens indicated by the increasing number of case reports on fusarioses over the years (Pubmed http://www.ncbi.nlm.nih.gov/pubmed data until October 2013).

identification of molecular siblings, the Translation elongation factor 1-alpha (TEF-1 $\alpha)$ region, or RNA polymerase II subunits 1 and $2(R P B 1$ and $R P B 2)$ are especially recommended [9]. A curated database allows for the comparison of found sequences with well-identified Fusarium isolates (http://www. cbs.knaw.nl/fusarium/2 [9].

Molecular identification techniques of Fusarium based on DNA polymorphisms have been developed for use on pure cultures. Direct sequencing of DNA in patient samples also provides an option [10]. Detection techniques include reverse line blotting (RLB) [11], loop-mediated isothermal amplification (LAMP) [12], or rolling circle amplification (RCA) [13]. Besides, multiplex DNA screenings have been developed. These methods may combine (tandem) polymerase chain reactions (PCR) reactions with flow cytometry and/or microarrays [14-18].

Other diagnostic tools in development focus on specific peptides or other metabolites produced by fungi. In particular, matrix-assisted laser desorption ionization time-of-flight (Maldi-TOF) mass spectrometry is being
B

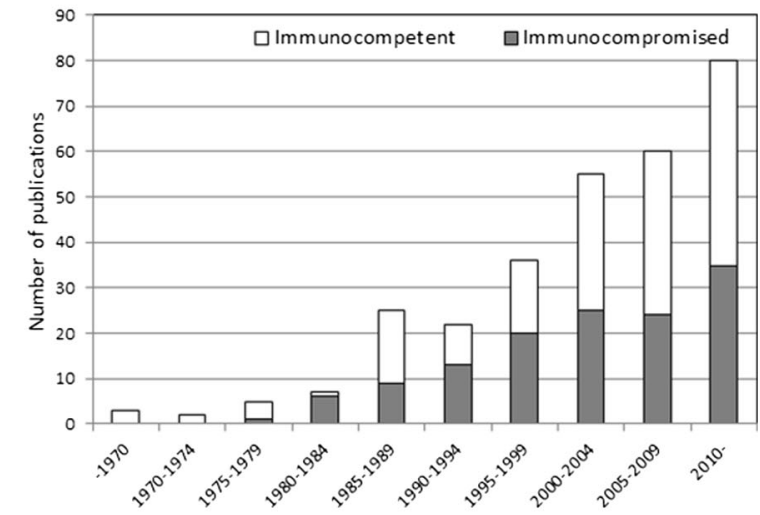

C

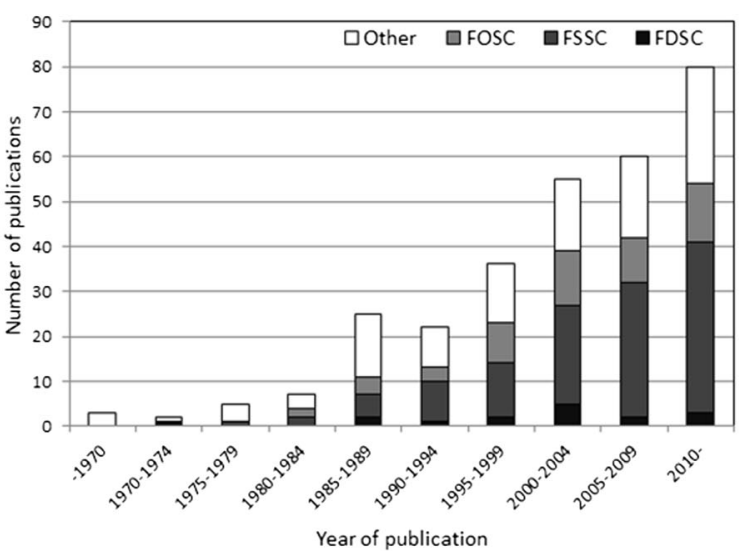

$b$ Both the numbers of infections in healthy individuals as well as in immunocompromised patients have increased. $c$ The majority of case reports were caused by members of the Fusarium solani species complex, followed by members of the Fusarium oxysporum species complex and other species

explored [19-21]. This technique is still restricted to the identification of pure cultures, while patient samples are still problematic.

\section{Emerging Opportunists—now and in the Future}

Members of the genus Fusarium have been involved in infections ranging from localized (nail, skin, eye, or other location), mainly in immunocompetent hosts, to disseminated infections in immunocompromised patients (for a review see e.g., [8] and below). Over the years, the number of case reports on fusarioses both in immunocompetent and compromised hosts has steadily increased (Fig. 1B; data until October 2013 from PubMed http:// www.ncbi.nlm.nih.gov/pubmed). About $40 \%$ of these reports were due to members of the FSSC, while the FOSC was involved in approximately $20 \%$ of these reports (Fig. 1C).

Species distributions in the different types of fusarioses have to be concluded from the few population studies done so far. Three studies focused on onychomycoses and skin infections in Italy [22], Switzerland [23], and Colombia 
[24], respectively (Table 1). Etiological agents belonged to FSSC causing $31-82 \%$ and FOSC $4-56 \%$ of infections, while members of the FFSC caused 2-37\%; only in one study a single member of the FDSC was found. The prevalence of onychomycoses in humans lies in the range of $5-15 \%$ of the adult population [29-31]. Many of these are caused by Candida or dermatophytes, but some studies indicate that Fusarium spp. can make up to $10-15 \%$ of the cases [van Diepeningen unpublished results, 20]. Suggested predisposing factors for onychomycosis in general include increasing age, but also immunosuppression, poor peripheral circulation, trauma, and tinea pedis [29].

Two studies focused on eye infections caused by Fusarium in India [25] and Mexico [26] reported that 75-82\% of the infections are caused by FSSC, $9-12 \%$ by FDSC, and then occasionally by members of FOSC, FFSC, and FIESC. Fungal keratitis is often linked with trauma, especially with vegetable or other organic matter. The infection is more common in tropical areas and in areas with a relatively large agrarian population. However, prevalence data are still approximate.

Lortholary et al. [27] focused on disseminated fusarioses in the immunocompromised host, where approximately one-third is caused by FSSC, another third by FFSC, and the remainder by FOSC, FDSC, or rarely by FIESC. Limited data exist on the prevalence of each species. Girmenia et al. [32] estimated a prevalence of $0.06 \%$ of fusarioses in patients with acute leukemia in Italy, while Nucci et al. [33] noted an increase in Brazil from 0.86 to 10.23 cases of fusariosis/1,000 hospital admissions in haemato-oncology wards. The one-year cumulative incidence of fusariosis in AML/MDS, allogeneic HCT, and autologous HCT patients proved to be $5.2,3.8$, and $0.6 \%(\mathrm{p}=0.01)$, respectively [34]. Disseminated infection in general seems to occur especially in haemato-oncological patients (Table 2). The numbers of cases in patients after a solid-organ transplant, HIV, or other reasons for immunodeficiency are much lower. Fusarioses in SOT recipients tend to remain localized, occur later in the post-transplantation period, and have a better outcome [86].

With ever-rising numbers of immunocompromised patients due to better treatment and survival rates, and also through better prophylaxis against Candida and Aspergillus, the prevalence of invasive fusariosis may rise further in the future. Primary cutaneous infections often prove to be the portal of entry for a disseminated fusariosis $[33,87]$. In return, disseminated infections lead to secondary cutaneous lesions [e.g., [88].

From a global comparison of the different studies of fusarioses, it can be deduced that there are regional differences in prevalent etiological agents (Table 1). For example, in Colombia the numbers of onychomycoses caused by FSSC are higher than in Europe [22-24]. Furthermore, some species complexes seem to be more often involved in certain types of infections; for instance, members of FFSC are relatively often involved in disseminated infections [27]. While members of FDSC seem to be more often involved in eye and disseminated infections than in onychomycoses.

\section{Clinical Spectra of Fusarium Species}

The Fusarium solani species complex (FSSC) globally is the most common group encountered in human infections. It contains sixty or more haplotypes, some of which are predominant in patients $[28,89]$. Of these, F. falciforme, F. keratoplasticum, F. lichenicola, and F. petroliphilum have been treated as separate species within FSSC, capable of human infection. Reported cases by members of FSSC range from onychomycosis to disseminated infection (see Table 2 for references). However, in most of the published cases no FSSC haplotypes were mentioned and sequences were not available. For this reason, they are listed in Table 2 as infections by F. solani sensu lato. Disseminated infections in patients with underlying diseases other than haematooncological disorders are rare, although a few cases of infection after solid organ transplant $[40,41]$ or in patients with auto-immune disorders [45] have been described.

At least 26 of the at least 256 DNA Sequence Types recognized within the cosmopolitan Fusarium oxysporum species complex (FOSC) have been involved in human infection [90]. Recognition of subgroups within FOSC has been restricted to formae speciales based on host plant specificity. The generalized name Fusarium oxysporum sensu lato has been used for the

Table 1 Incidence of the different Fusarium species (complexes) in different types of fusarioses, based on different population studies

\begin{tabular}{|c|c|c|c|c|c|c|c|}
\hline Geographic location & Italy[22] & Switzerland[23] & Colombia[24] & India[25] & Mexico[26] & France[27] & USA[28] \\
\hline Type of fusariosis & Skin/Nail & Nail & Nail & Eye & Eye & Disseminated & All \\
\hline \multicolumn{8}{|l|}{ Species complexes } \\
\hline F. solani $\mathrm{SC}$ - FSSC & $31 \%$ & $33 \%$ & $65 \%$ & $75 \%$ & $82 \%$ & $36 \%$ & $60 \%$ \\
\hline F. oxysporum SC - FOSC & $34.5 \%$ & $56 \%$ & $33 \%$ & $4 \%$ & $6 \%$ & $16 \%$ & $10 \%$ \\
\hline G. fujikuroi SC - GFSC & $34.5 \%$ & $9 \%$ & $2 \%$ & $9 \%$ & 0 & $37 \%$ & $10 \%$ \\
\hline F. dimerum SC - FDSC & 0 & $2 \%$ & 0 & $9 \%$ & $12 \%$ & $9 \%$ & $5 \%$ \\
\hline F. chlamydosporum SC - FCSC & 0 & 0 & 0 & 0 & 0 & 0 & \multirow{2}{*}{$15 \%$} \\
\hline F. incarnatum-equiseti SC - FIESC & 0 & 0 & 0 & $3 \%$ & 0 & $2 \%$ & \\
\hline
\end{tabular}


Table 2 Clinical spectrum and the geographical occurrence of the different etiological agents found within the genus Fusarium, based on case report and population study data. In light grey are infections that have only been described in a single case report or single population study; in dark grey are the more frequent infections

\begin{tabular}{|c|c|c|c|c|c|c|c|c|c|c|c|}
\hline \multirow{3}{*}{$\begin{array}{l}\text { Species } \\
\text { Complex }\end{array}$} & \multirow[t]{3}{*}{ Species } & \multicolumn{7}{|c|}{ Clinical spectrum } & \multicolumn{3}{|l|}{ Occurrence in Nature } \\
\hline & & \multirow[t]{2}{*}{$\begin{array}{l}\text { Onycho } \\
\text { mycosis }\end{array}$} & \multirow[t]{2}{*}{$\begin{array}{l}\text { Skin } \\
\text { infection }\end{array}$} & \multirow{2}{*}{\multicolumn{2}{|c|}{$\begin{array}{l}\text { Keratitis Deep, } \\
\text { +endoph localized } \\
\text { thalmitis }\end{array}$}} & \multicolumn{3}{|c|}{ Disseminated } & \multirow[t]{2}{*}{$\begin{array}{l}\text { Spread [\#25; unless } \\
\text { stated otherwise] }\end{array}$} & \multirow[t]{2}{*}{ Reported Clinical cases } & \multirow[t]{2}{*}{$\begin{array}{l}\text { s Main habitat [\#25; } \\
\text { unless stated } \\
\text { otherwise] }\end{array}$} \\
\hline & & & & & & $\begin{array}{l}\text { Haemato } \\
\text { /onco }\end{array}$ & SOT & other & & & \\
\hline \multirow[t]{5}{*}{$\overline{\mathrm{FSSC}}$} & F. solani sensu latu & [30] & [69] & [47] & {$[72]$} & [70](involvi & {$[64],[67]$,} & & Worldwide & Worldwide & soil \& plant spp. \\
\hline & F. falciforme & Pers. Obs & Pers. Obs & [13] & [56] & [82] & & [57] & Worldwide \#63 & Worldwide & Soil, human \#63 \\
\hline & F. keratoplasticum & Pers. Obs & [58] & {$[58]$} & [58] & [58] & & & Worldwide \#7,\#58 & Worldwide & Diverse: soil, human, \\
\hline & F. lichenicola & & {$[60]$} & [59] & [61] & [62] & & & Worldwide \#63 & Worldwide & Soil, human \#63 \\
\hline & F. petroliphilum & & & [58] & [58] & Pers. Obs & & & Worldwide \#7,\#58 & Worldwide & (Oil-poluted) soil, plants, \\
\hline FOSC & F. oxysporum sensu latu & $\begin{array}{c}{[10],[11],} \\
{[40]}\end{array}$ & [73] & {$[34],[47]$} & {$[53],[74]$} & {$[75],[76]$} & [67] & {$[65],[66]$} & Worldwide & Worldwide & Soil\& plant wilt pathogen \\
\hline \multirow[t]{3}{*}{$\overline{\text { FDSC }}$} & F. dimerum & {$[40],[51]$} & [52] & {$[47],[34]$} & [53] & [54] & & & Worldwide & Worldwide & Soil \\
\hline & F. delphinoides & & & [51] & & [51] & & & Worldwide \#51 & Worldwide & Soil, plant pathogen chick \\
\hline & F. penzigii & & & [51] & & & & & England, Sri Lanka \#51 & Sri Lanka \#51 & Wood/Fagus associated \#51 \\
\hline FCSC & F. chlamydosporum & [40] & [8] & [34] & [55] & [8] & & & (Semi)arid regions & USA, South Africa, Brazil & Soil, saprophyte \\
\hline \multirow[t]{2}{*}{ FIESC } & F. incarnatum & [40] & [78] & [34] & [79] & [8] & & & Worldwide & Worldwide & Soil, plants \\
\hline & F. equiseti & [80] & [52] & [8] & [8] & [81] & & & Worldwide & Worldwide & Soil, plants, secondary \\
\hline \multirow[t]{10}{*}{$\overline{F F S C}$} & F. acutatum & & & & [26] & & & & India, Pakistan & Qatar & Cajanus and wheat (aphids) \\
\hline & F. anthophilum & & & & Gangrenou & [27] & & & Cosmopolitan (temperate) & Japan & Various plant spp. \\
\hline & F. andiyazi & & & & & [28] & & & America, Africa, Asia & Turkey & Sorghum, rice, figs \\
\hline & F. napiforme & & & & [29] & [30] & & & Africa, Argentina, Australia & USA, South Korea & Soil, sorghum, millet and \\
\hline & F. nygamai & [31] & & & [32] & & & & Hot, arid locations & Colombia, NL/Egypt & Sorghum, cotton, cereal \\
\hline & F. proliferatum & [31] & & [37] & [38] & $\# 39$ & & & Worldwide & Worldwide & Many substrates, maize, \\
\hline & F. sacchari & [40] & [10] & [41] & [42] & & & & Asia, America & Brazil, Europe, India & Sugar cane, sorghum, maize \\
\hline & F. subglutinans & & & [43] & [44] & & & & Cooler regions & China, Europe & Especially on maize \\
\hline & F. thapsinum & & & [83] & & [84] & & & \multicolumn{2}{|c|}{ Warmer climates worldwide Turkey, China } & Sorghum \\
\hline & F. verticillioides & [40] & [10] & [47] & [85] & [14] & & & Worldwide & Americas, Europe & Especially on maize \\
\hline FSAMSC & F. sporotrichioides & & [49] & & [50] & & & & Widespread, temperate & Japan, Turkey & Diverse substrates \\
\hline FASC & F. avenaceum & [36] & & & [36] & & & & Temperate regions & Japan & Soil, different plant species \\
\hline$\overline{\text { FLSC }}$ & F. lateritium & & & [34] & & & & [35] & Worldwide & South Africa, Brazil & Soil, woody plants \\
\hline FFSC & F. polyphialidicum & & & [33] & & & & & Europe, Africa, Australia & Spain & Soil, sorghum \\
\hline
\end{tabular}

aggregate. Also, fusarioses caused by members of the FOSC range from onychomycosis to disseminated infection, but the latter occurred not only in haemato-oncological [e.g., [57, 58], but also in SOT [41] and HIV [59] patients, as well as in an individual suffering from a heatstroke [60].

The Fusarium dimerum species complex (FDSC) contains at least 12 lineages, of which at least $F$. dimerum sensu stricto, $F$. delphinoides, and $F$. penzigii have been involved in human infection [61]. Most case reports on $F$. dimerum were published prior to its recognition as a species complex. Also, in this species complex the infections range from onychomycoses, keratitis, and other localized infections to disseminated infections in haemato-oncological patients.

Fusarium chlamydosporum has been named after its fast and abundant production of thick-walled chlamydospores in mycelium as well as in macroconidia [7]. The Fusarium chlamydosporum species complex (FCSC) (F. chlamydosporum sensu lato) contains at least four distinct species [28]. The complex has only once been implicated in a keratitis [54], but more often in onychomycoses, cutaneous and deep localized infections, and in disseminated infections in haemato-oncological patients [28, 35, 64].
Within the Fusarium incarnatum-equiseti species complex (FIESC) and using four loci, at least 28 species can be recognized, which are organized into two main clades [28]. Haplotypes 1-14 [28] are molecular siblings of $F$. equiseti, while the remaining species are grouped as ' $F$. incarnatum' or ' $F$. semitectum' $[7,28]$. Representatives of the two groups have repeatedly been involved in onychomycoses, skin, eye, and deep localized and disseminated infections, especially in leukemic patients.

The two members of the Fusarium fujikuroi species complex (FFSC) that are most commonly observed in human infections are $F$. proliferatum and $F$. verticillioides. However, members of FFSC are increasingly identified in especially invasive and disseminated infections in haematooncological patients (Table 2). Many environmental Fusarium species and the human infections they cause have a worldwide distribution (Table 2). However, some species of FFSC species, e.g., F. acutatum, F. anthophilum, $F$. andiyazi, F. nygamai, and $F$. sacchari have a limited geographic distribution and/or are associated with specific climatic conditions. For some of the species, distributions 
of environmental and clinical strains are concordant (e.g., $F$. andiyazi, F. subglutinans, and $F$. thapsinum), whereas in others the reported clinical cases indicate an expansion outside previously known borderlines (e.g., F. acutatum and $F$. napiforme). Fusarium nygamai, known from hot and arid climates, caused a disseminated infection in a patient from The Netherlands in Northern Europe, but this infection was presumably contracted during a recent holiday in Egypt [75].

Fusarium sporotrichioides is closely related to Fusarium poae and F. langsethiae and is located in the Gibberella-clade of Fusarium [91]. The species is known to produce T-2 and HT-2 mycotoxins [91], and thus far, two localized infections have been described: an ulcerative dermatitis [92], and a pedal lesion in a diabetic [93].

Outside the above-described species complexes, a few other Fusarium species have been implicated in humans and other mammals. A strain of $F$. avenaceum caused an infection of the claw of a dog, finally leading to osteomyelitis [94]. Both F. lateritium and F. polyphialidicum were recorded causing keratitis [54, 95], while $F$. lateritium also caused a disseminated infection in an HIV-patient [96].

\section{Conclusions}

Within the group of fungi we elect to call Fusarium, many species and species complexes have been involved in opportunistic human infections. Species recognition by morphological characters is difficult, as strains may be slow in forming distinguishing structures and in particular, clinical isolates may be pionnotal. Observed fusarioses range from onychomycoses, skin infections and keratitis, mainly in healthy individuals, to deep local and disseminated infections in the immunocompromised. The disseminated infections predominately occur especially in leukemic patients and have a high mortality rate. Many of the opportunistic species complexes seem, in principle, able to cause the whole range of fusariosis types. However, significant differences exist in the main species complexes in classes of infections observed locally (Table 1 ).

An important question is whether we need to identify the etiological agent of a fusariosis to the species level. In general, as many other members of the order Hypocreales, Fusarium species are highly refractory to antifungal therapy. Only few antifungal drugs-amphothericin, voriconazole and terbinafine-seem effective [89], and variation can be observed between and within species and species complexes [e.g., [25, 29, 48, 67]. To reveal small differences in susceptibility between clinically relevant Fusarium species, precise identification of siblings is recommended.
Acknowledgments Balázs Brankovics was supported by the Division for Earth and Life Sciences (ALW) with financial aid from the Netherlands Organization for Scientific Research (NWO) (Dossier 833.13.006).

\section{Compliance with Ethics Guidelines}

Conflicts of Interest Anne D. van Diepeningen' Abdullah M.S. Al-Hatmi, Balázs Brankovics, and G. Sybren de Hoog have declared no conflicts of interest.

Human and Animal Rights and Informed Consent This article does not contain any studies with human or animal subjects performed by any of the authors.

Open AccessThis article is distributed under the terms of the Creative Commons Attribution License which permits any use, distribution, and reproduction in any medium, provided the original author(s) and the source are credited.

\section{References}

Papers of particular interest, published recently, have been highlighted as:

- Of importance

1. Hawksworth DL. A new dawn for the naming of fungi: impacts of decisions made in Melbourne in July 2011 on the future publication and regulation of fungal names. IMA Fungus. 2011;2:155-62.

2. Geiser DM, Aoki, Bacon CW, et al. One Fungus, One Name: Defining the genus Fusarium in a scientifically robust way that preserves longstanding use. Phytopathology. 2013;103(5):400-8. This paper sets the agreement to keep the name Fusarium a large genus, including all the clinical Fusarium species described in this paper.

3. De Hoog GS, Haase G, Chaturvedi V, Walsh TJ, Meyer W, Lackner M. Taxonomy of medically important fungi in the molecular era. The Lancet Infectious Diseases. 2013;13(5):385-6. Plea for more nomenclatural stability for clinically important species.

4. Taylor JW, Jacobson DJ, Kroken S, Kasuga T, Geiser DM, Hibbett DS, et al. Phylogenetic species recognition and species concepts in fungi. Fungal Genet Biol. 2000;31:21-32.

5. Short DP, O'Donnell K, Thrane U, et al. Phylogenetic relationships among members of the Fusarium solani species complex in human infections and the descriptions of F. keratoplasticum sp. nov. and F. petroliphilum stat. nov. Fungal Genet Biol. 2013;53:59-70.

6. O'Donnell K, Rooney AP, Proctor RH, et al. RPB1 and RPB2 phylogeny supports an early Cretaceous origin and a strongly supported clade comprising all agriculturally and medically important fusaria. Fungal Genet Biol. 2012. doi:10.1016/j.fgb.2012.12.004.

7. Leslie JF, Summerell BA. The Fusarium laboratory manual. Oxford: Blackwell Publishing Ltd; 2006.

8. De Hoog GS, Guarro J, Gené J, Figueras MJ. Atlas of Clinical Fungi. 3rd ed. Utrecht: CD-ROM, CBS-KNAW Fungal Biodiversity Centre; 2011.

9. O'Donnell K, Sutton DA, Rinaldi, et al. Internet-accessible DNA sequence database for identifying Fusaria from human and animal infections. Journal of Clinical Microbiology. 2010;48:3708-18.

10. Palmore TN, Shea YR, Childs RW, Sherry RM, Walsh TJ. Fusarium proliferatum soft tissue infection at the site of a puncture by a plant: recovery, isolation, and direct molecular identification. $\mathrm{J}$ Clin Microbiol. 2010;48(1):338-42. 
11. Wang H, Xiao M, Kong F, et al. Accurate and practical identification of 20 Fusarium species by seven-locus sequence analysis and reverse line blot hybridization, and an in vitro antifungal susceptibility study. J Clin Microbiol. 2011;49(5):1890-8.

12. Niessen L, Vogel RF. Detection of Fusarium graminearum DNA using a loop-mediated isothermal amplification (LAMP) assay. Int $\mathbf{J}$ Food Microbiol. 2010;140(2-3):183-91.

13. Davari $\mathrm{M}$, van Diepeningen $\mathrm{AD}$, Babai-Ahari A, et al. Rapid identification of Fusarium graminearum species complex using Rolling Circle Amplification (RCA). J Microbiol Methods. 2012;89(1):63-70.

14. Buelow DR, Gu Z, Walsh TJ, Hayden RT. Evaluation of multiplexed PCR and liquid-phase array for identification of respiratory fungal pathogens. Med Mycol. 2012;50(7):775-80.

15. He D, Hao J, Zhang B, et al. Pathogenic spectrum of fungal keratitis and specific identification of Fusarium solani. Invest Ophthalmol Vis Sci. 2011;52(5):2804-8.

16. Lau A, Sorrell TC, Chen S, Stanley K, Iredell J, Halliday C. Multiplex tandem PCR: a novel platform for rapid detection and identification of fungal pathogens from blood culture specimens. J Clin Microbiol. 2008;46(9):3021-7.

17. Spiess B, Seifarth W, Hummel M, et al. DNA microarray-based detection and identification of fungal pathogens in clinical samples from neutropenic patients. J Clin Microbiol. 2007;45(11):3743-53.

18. Liao MH, Lin JF, Li SY. Application of a multiplex suspension array for rapid and simultaneous identification of clinically important mold pathogens. Mol Cell Probes. 2012;26(5):188-93.

19. De Carolis E, Posteraro B, Lass-Flörl C, et al. Species identification of Aspergillus, Fusarium and Mucorales with direct surface analysis by matrix-assisted laser desorption ionization time-of-flight mass spectrometry. Clin Microbiol Infect. 2012;18(5):475-84.

20. Marinach-Patrice C, Lethuillier A, Marly A, et al. Use of mass spectrometry to identify clinical Fusarium isolates. Clin Microbiol Infect. 2009;15(7):634-42.

21. Seyfarth F, Ziemer M, Sayer HG, et al. The use of ITS DNA sequence analysis and MALDI-TOF mass spectrometry in diagnosing an infection with Fusarium proliferatum. Exp Dermatol. 2008;17(11):965-71.

22. Migheli Q, Balmas V, Harak H, et al. Molecular Phylogenetic Diversity of Dermatologic and Other Human Pathogenic Fusarial Isolates from Hospitals in Northern and Central Italy. J Clin Microbiol. 2010;48:1076-84.

23. Ninet B, Jan I, Bontems O, et al. Molecular identification of Fusarium species in onychomycoses. Dermatology. 2005;210:215.

24. Castro López N, Casas C, Sopo L, et al. Fusarium species detected in onychomycosis in Colombia. Mycoses. 2008;52:350-6.

25. Homa M, Shobana CS, Singh YR, et al. Fusarium keratitis in South India:causative agents, their antifungal susceptibilities and a rapid identification method for the Fusarium solani species complex. Mycoses. 2013;56:501-11.

26. Vanzzini Zago V, Manzano-Gayosso $\mathrm{P}$, Hernández-Hernández F, Méndez-Tovar LJ, Gómez-Leal A, López MR. Queratomicosis en un centro de atención oftalmológica en la Ciudad deMéxico. Rev Iberoam Micol. 2010;27:57-61.

27. Lortholary O, Obenga G, Biswas P, et al. International retrospective analysis of 73 cases of invasive fusariosis treated with voriconazole. Antimicrob Agents Chemother. 2010;54:4446-50.

28. O'Donnell K, Sutton DA, Rinaldi MG, Gueidan C, Crous PW, Geiser DM. Novel Multilocus Sequence Typing Scheme Reveals High Genetic Diversity of Human Pathogenic Members of the Fusarium incarnatum-F. equiseti and F. chlamydosporum Species complexes within the United States. Journal of Clinical Microbiology. 2009;47:3851-61.

29. Ghannoum MA, Hajjeh RA, Scher R. A large scale North American study of fungal isolates from nails: the frequency of onychomycosis, fungal distribution, and antifungal susceptibility patterns. J Am Acad Dermatol. 2000;43:641-8.

30. Ellis DH, Watson AB, Marley JE, Williams TG. Nondermatophytes in onychomycosis of the toenails. Br J Dermatol. 1997;136:490-3.

31. Heikkilä H, Stubb S. The prevalence of onychomycosis in Finland. Br J Dermatol. 1995;133:699-703.

32. Girmenia C, Pagano L, Corvatta L, Mele L, del Favero A, Martino P. The epidemiology of fusariosis in patients with haematological diseases. Gimema Infection Programme. Br J Haematol. 2000;111(1):272-6.

33. Nucci M, Varon AG, Garnica M, et al. Increased incidence of invasive fusariosis with cutaneous portal of entry. Brazil Emerg Infect Dis. 2013;19(10):1567-72.

34. Nucci M, Garnica M, Gloria AB, et al. Invasive fungal diseases in haematopoietic cell transplant recipients and in patients with acute myeloid leukaemia or myelodysplasia in Brazil. Clin Microbiol Infect. 2013;19(8):745-51.

35. Guilhermetti E, Takahachi G, Shinobu CS, Svidzinski TI. Fusarium spp. as agents of onychomycosis in immunocompetent hosts. Int J Dermatol. 2007;46:822-6.

36. Banerji JS, Singh JC. Cutaneous Fusarium infection in a renal transplant recipient: a case report. J Med Case Reports. 2011;5:205.

37. Zapater RC. Opportunistic fungus infection - Fusarium infections -keratomycosis by Fusarium. Japanese Journal of Medical Mycology. 1986;27:68-9.

38. Hsiue HC, Ruan SY, Kuo YL, Huang YT, Hsueh PR. Invasive infections caused by non-Aspergillus moulds identified by sequencing analysis at a tertiary care hospital in Taiwan, 2000-2008. Clin Microbiol Infect. 2010;16:1204-6.

39. Vincent AL, Cabrero JE, Greene JN, Sandin RL. Successful voriconazole therapy of disseminated Fusarium solani in the brain of a neutropenic cancer patient. Cancer Control. 2003;10: 414-9.

40. Guinvarc'h A, Guilbert L, Marmorat-Khuong A, et al. Disseminated Fusarium solani infection with endocarditis in a lung transplant recipient. Mycoses. 1998;1(1-2):59-61.

41. Park BJ, Pappas PG, Wannemuehler KA, et al. Invasive nonAspergillus mold infections in transplant recipients, United States, 2001-2006. Emerg Infect Dis. 2011;17(10):1855-64. doi:10.3201/ eid1710.110087.

42. Lodato F, Tamé MR, Montagnani M, et al. Systemic fungemia and hepatic localizations of Fusarium solani in a liver transplanted patient: an emerging fungal agent. Liver Transpl. 2006;12:1711-4.

43. Van Etta LL, Peterson LR, Gerding DN. Acremonium falciforme (Cephalosporium falciforme) mycetoma in a renal transplant patient. Arch Dermatol. 1983;119(8):707-8.

44. Yun SJ, Shin MG, Choi C, et al. Fatal disseminated angioinvasive Fusarium falciforme infection in a patient with acute myeloid leukaemia. Br J Dermatol. 2007;157(2):407-9.

45. Edupuganti S, Rouphael N, Mehta A, et al. Fusarium falciforme Vertebral Abscess and Osteomyelitis:Case Report and Molecular Classification. J Clin Microbiol. 2011:49:2350-3.

46. Summerbell RC, Schroers HJ. Analysis of phylogenetic relationship of Cylindrocarpon lichenicola and Acremonium falciforme to the Fusarium solani species complex and a review of similarities in the spectrum of opportunistic infections caused by these fungi. J Clin Microbiol. 2002;40(8):2866-75.

47. Short DPG, O’Donnell K, Thrane U, et al. Phylogenetic relationships among members of the Fusarium solani species complex in human infections and the descriptions of $F$. keratoplasticum sp. Nov. and F. petrophilum stat.nov. Fungal Genetics and Biology. 2013;53:59-70.

48. O'Donnell K, Sutton DA, Fothergill A, et al. Molecular phylogenetic diversity, multilocus haplotype nomenclature, and in vitro 
antifungal resistance within the Fusarium solani species complex. J Clin Microbiol. 2008;6:2477-90.

49. Iwen PC, Tarantolo SR, Sutton DA, Rinaldi MG, Hinrichs SH. Cutaneous infection caused by Cylindrocarpon lichenicola in a patient with acute myelogenous leukemia. Journal of Clinical Microbiology. 2000;38:3375-8.

50. Mangiaterra M, Giusiano G, Smilasky G, Zamar L, Amado G, Vincentín C. Keratomycosis caused by Cylindrocarpon lichenicola. Med Mycol. 2001;39:143-5.

51. Sharma R, Farmer CK, Gransden WR, Ogg CS. Peritonitis in continuous ambulatory peritoneal dialysis due to Cylindrocarpon lichenicola infection. Nephrology, Dialysis, Transplantation. 1998;13:2662-4.

52. James EA, Orchard K, McWhinney PH, et al. Disseminated infection due to Cylindrocarpon lichenicola in a patient with acute myeloid leukaemia. J Infect. 1997;34(1):65-7.

53. Assaf C, Goerdt S, Seibold M, Orfanos C. Clinical picture: Cutaneous hyalohyphomycosis. Lancet. 2000;356:1185.

54. Naiker S, Odhav B. Mycotic keratitis:profile of Fusarium species and their mycotoxins. Mycoses. 2004;47:50-6.

55. Krcmery Jr V, Jesenska Z, Spanik S, et al. Fungaemia due to Fusarium spp. in cancer patients. Journal of Hospital Infections. 1997:36:223-8.

56. García-Martos P, Gil de Sola F, Marín P, et al. Fungal peritonitis in ambulatory continuous peritoneal dialysis: description of 10 cases. Nefrologia. 2009;29:534-9. in Spanish.

57. Albisetti M, Lauener RP, Güngör T, Schär G, Niggli FK, Nadal D. Disseminated Fusarium oxysporum infection in hemophagocytic lymphohistiocytosis. Infection. 2004;32:364-6.

58. Durand-Joly I, Alfandari S, Benchikh Z, et al. Successful outcome of disseminated Fusarium infection with skin localization treated with Voriconazole and Amphotericin B-lipid complex in a patient with acute leukemia. J Clin Microbiol. 2004;41:4898-900.

59. Eljaschewitsch J, Sandfort J, Tintelnot K, Horbach I, Ruf B. Port-acath-related Fusarium oxysporum infection in an HIV-infected patient:treatment with liposomal amphotericin B. Mycoses. 1996;39(3-4):115-9.

60. Sturm AW, Grave W, Kwee WS. Disseminated Fusarium oxysporum infection in patient with heatstroke. Lancet. 1989;1(8644):968.

61. Schroers HJ, O'Donnell K, Lamprecht SC, et al. Taxonomy and phylogeny of the Fusarium dimerum species group. Mycologia. 2009;101:44-70.

62. Goldschmied-Reouven A, Friedman J, Block CS. Fusarium specie isolated from non-ocular sites:a 10-year experience at an Israeli general hospital. Journal de Mycologie Médicale. 1993;3:99-102.

63. Letscher-Bru V, Campos F, Waller J, Randriamahazaka R, Candolfi E, Herbrecht R. Successful outcome of treatment of a disseminated infection due to Fusarium dimerum in a Leukemia patient. J Clin Microbiol. 2002;40:1100-2.

64. Kiehn TE, Nelson PE, Bernard EM, Edwards FF, Koziner B, Armstrong D. Catheter-associated fungemia caused by Fusarium chlamydosporum in a patient with lymphocytic lymphoma. Journal of Clinical Microbiology. 1985;21:501-4.

65. Imwidthaya S, Chuntrasakul C, Chantarakul N. Opportunistic fungal infection of the burn wound. J Med Assoc Thai. 1984;67:242-8.

66. McGinnis MR, Severo LC, Kalil R, Faleiro PT. Endocarditis caused by Fusarium pallidoroseum. Journal de Mycologie Médicale. 1994;4:45-7.

67. Alastruey-Izquierdo A, Cuenca-Estrella M, Monzón A, Mellado E, Rodríguez-Tudela JL. Antifungal susceptibility profile of clinical Fusarium spp. isolates identified by molecular methods. Journal of Antimicrobial Chemotherapy. 2008;61:805-9.

68. Boutati EI, Anaissie EJ. Fusarium, a significant emerging pathogen in patients with hematologic malignancy: ten years' experience at a cancer center and implications for management. Blood. 1997;90: 999-1008.

69. Taj-Aldeen SD, Gene J, Al Bozom I, Buzina W, Cano JF, Guarro J. Gangrenous necrosis of the diabetic foot caused by Fusarium acutatum. Med Mycol. 2006;44:547-52.

70. Okuda C, Ito M, Sato Y, Oka K, Hotchi M. Disseminated cutaneous Fusarium infection with vascular invasion in a leukemic patient. Journal of Medical and Veterinary Mycology. 1987;25: $177-86$.

71. Kebabcı N, van Diepeningen AD, Ener B, et al. Fatal break-through infection with Fusarium andiyazi:new multi-resistant etiological agent cross-reacting with Aspergillus galactomannan enzyme immunoassay. Mycoses. 2013. doi:10.1111/myc.12142.

72. Lee SK, Kim SS, Nahm DH, et al. Hypersensitivity pneumonitis caused by Fusarium napiforme in a home environment. Allergy. 2000;55:1190-3.

73. Melcher GP, McGough DA, Fothergill AW, Norris C, Rinaldi MG Disseminated hyalohyphomycosis caused by a novel human pathogen, Fusarium napiforme. Journal of Clinical microbiology. 1993;31:1461-7.

74. Bueno JG, Martinez C, Zapata B, Sanclemente G, Gallego M, Mesa AC. In vitro activity of fluconazole, itraconazole, voriconazole and terbinafine against fungi causing onychomycosis. Clinial and Experimental Dermatology. 2010;35:658-63.

75. Krulder JW, Brimicombe RW, Wijermans PW, Gams W. Systemic Fusarium nygamai infection in a patient with lymphoblastic nonHodgkin's lymphoma. Mycoses. 1996;39:121-3.

76. Ferrer C, Alio J, Rodriguez A, Andreu M, Colom F. Endophthalmitis Caused by Fusarium proliferatum. Journal of Clinical Microbiology. 2005;43:5372-5.

77. Murray CK, Beckius ML, McAllister K. Fusarium proliferatum superficial suppurative thrombophlebitis. Military Medicine. 2003; $168: 426$

78. Summerbell RC, Richardson SE, Kane J. Fusarium proliferatum as an agent of disseminated infection in an immunosuppressed patient. Journal of clinical Microbiology. $1988 ; 26: 82-7$

79. Chander J, Singla N, Gulati N, Sood S. Fusarium sacchari:A cause of exogenous fungal endophthalmitis:First case report and review of literature. Mycopathologia. 2011;171:431-4.

80. Guarro J, Nucci M, Akiti T, et al. Fungemia due to Fusarium sacchari in an immunosuppressed patient. J Clin Microbiol. 2000;38:419-21.

81. Polenghi F, Lasagni A. Observations on a case of mycokeratitis and its treatment with BAY b 5097 (Canesten). Mykosen. 1976;19:223-6.

82. Chen QX, Li CX, Huang WM, Shi JQ, Li SF. Cutaneous hyalohyphomycosis caused by Fusarium subglutinans. European Journal of Dermatology. 2010;20:526-7.

83. Yücesoy M, Ergon MC, Oren H, Gülay Z. Case report:a Fusarium fungaemia. Mikrobiyol Bul. 2004;38:265-71. in Turkish.

84. Wang H, Xiao M, Kong F, Chen S, Dou HT, Sorrell T, et al. Accurate and practical identification of 20 Fusarium species by Seven-Locus Sequence Analysis and Reverse Line Blot Hybridization, and an in vitro antifungal susceptibility study. J Clin Microbiol. 2011;49:1890-9.

85. Ajello L, Padhye AA, Chandler FW, McGinnis MR, Morganti L, Alberici F. Fusarium moniliforme, a new mycetoma agent. Restudy of a European case. European Journal of Epidemiology. 1985; $1: 5-10$

86. Sampathkumar P, Paya CV. Fusarium infection after solid-organ transplantation. Clin Infect Dis. 2001;32(8):1237-40.

87. Varon AG, Nouer SA, Barreiros G, et al. Superficial skin lesions positive for Fusarium are associated with subsequent development of invasive fusariosis. J Infect. 2013. doi:10.1016/j.jinf.2013.08. 011. 
88. Tiribelli M, Zaja F, Filì C, et al. Endogenous endophthalmitis following disseminated fungemia due to Fusarium solani in a patient with acute myeloid leukemia. European Journal of Haematology. 2002;68:314-7.

89. Guarro J. Fusariosis, a complex infection caused by a high diversity of fungal species refractory to treatment. Eur. J. Clin. Microbiol. Infect. Dis. 2013 http://link.springer.com/article/10.1007\% 2Fs10096-013-1924-7.

90. O'Donnell K, Gueidan C, Sink S, et al. A two-locus DNA sequence database for typing plant and human pathogens within the Fusarium oxysporum species complex. Fungal Genetics and Biology. 2009;46:936-48.

91. Knutsen AK, Torp M, Holst-Jensen A. Phylogenetic analyses of the Fusarium poae, Fusarium sporotrichioides and Fusarium langsethiae species complex based on partial sequences of the translation elongation factor-1 alpha gene. Int J Food Microbiol. 2004;95(3):287-95.
92. Kano R, Maruyama H, Kubota M, Hasegawa A, Kamata H. Chronic ulcerative dermatitis caused by Fusarium sporotrichioides. Medical Mycology. 2011;49:303-5.

93. Özyurt M, Ardıç N, Turan K, et al. The isolation of Fusarium sporotrichioides from a diabetic foot wound sample and identification. Marmara Medical Journal. 2008;2:68-72.

94. Namitome K, Kano R, Sekiguchi M, et al. Isolation of Fusarium sp. from a claw of a dog with onychomycosis. Journal of Veterinary Medicine and Science. 2011;73:965-9.

95. Guarro J, Rubio C, Gené J, et al. Case of Keratitis Caused by an Uncommon Fusarium Species. Journal of Clinical Microbiology. 2003;41:5823-6.

96. Cambuim IIFN, Neves RP, de Queiroz LA, Magalhães OMC, Lima DMM. Fusarium lateritium (NEES) as an agent of fungemia in a patient infected with the human immunodeficiency virus (HIV). Brazilian Journal of Microbiology. 2007;38:285-6. 